\title{
Effect of tube spacing, fin density and Reynolds number on overall heat transfer rate for in-line configuration
}

\author{
Tahseen A. Tahseen ${ }^{1}$, M.M. Rahman ${ }^{2,3 *}$ and M. Ishak ${ }^{2}$ \\ ${ }^{1}$ Faculty of Mechanical Engineering \\ ${ }^{1}$ Department of Mechanical Engineering, College of Engineering, \\ Tikrit University, Tikrit, Iraq \\ ${ }^{2}$ Faculty of Mechanical Engineering, Universiti Malaysia Pahang, \\ 26600 Pekan, Pahang, Malaysia \\ Email: mustafizur@ump.edu.my \\ Phone: +6094246239; Fax: +6094246222 \\ ${ }^{3}$ Automotive Engineering Centre, Universiti Malaysia Pahang \\ 26600 Pekan, Pahang, Malaysia
}

\begin{abstract}
This paper presents variation of overall dimensionless heat transfer rate against dimensionless tubes spacing, fins density, Reynolds number for in-line configuration. Influence of Reynolds number on the predicted and experimental results of dimensionless pumping power minimization for with respect to the dimensionless fins density for several tube-to-tube spacing also investigated. The experiments were conducted at a flat tube in the flow direction, and Reynolds number based on the hydraulic diameter $\left(R e_{D h}\right)$ was considered. The dimensionless overall heat transfer rate is always increases with an increase of the Reynolds number. The dimensionless fins spacing effect on the dimensionless overall heat transfer rate increase is noticeable at high Reynolds numbers. The dimensionless pumping power increases with increasing response Reynolds numbers for dimensionless tubes spacing and dimensionless fins density. The dimensionless pumping power decreased with increase of dimensionless fin density.
\end{abstract}

Keywords: Heat transfer rate; fin density; fin spacing; Reynolds number; In-line configuration.

\section{INTRODUCTION}

A significant amount of research work carried out to improve the efficiency of heat exchangers due to a widespread used in industrial, transportation as well as domestic applications including thermal power plants, means of transport, heating and air conditioning systems, electronic equipment and space vehicles [1-4]. Because of their extensive use, increase in their efficiency would consequently reduce cost, space and materials required drastically [5]. The demand for an increase in energy has been rising in all facets of society. The answer to this demand is intelligent use of available energy. Flat tubes are vital components in various technical applications like modern heat exchangers and automotive radiators. Even though many researchers have devoted their work to study the fluid flow and heat transfer over objects of various shapes, flat tubes have not been investigated as much [6,7]. Flat tube designs are a recent addition for use in automotive air conditioning evaporators and condensers. Their cost has been reduced 
owing to developments in automotive brazed aluminium manufacturing technology [8]. The increase heat transfer gain and reduction of pressure drop in any tube banks configuration using a heat exchanger regardless of tube shaped the important issue for the design. Besides, the reduction of the volume for any thermal system is an important subject in any system design.

A review of the heat transfer and pressure drop in un-finned and finned and tube heat exchangers with circular tube experimental measurements in the relevant literature [9-11]. The relationship was established for the heat transfer and pressure drop. Regardless of the influence of tube diameter, the severity of the turbulence within the bundle depends on the velocity of the air and tube spacing. Thus, these parameters have a strong effect on the pressure drop in the banks of tubes. When the transverse pitch of the tube was changed, the existence of a clear influence on the pressure drop at the sideair was observed, while there was a lack of significant change in the heat transfer performance [12]. For the staggered configuration, the heat transfer coefficient is bigger for the nearer transverse pitch $[12,13]$. It would appear that the air velocity at the smallest channel between the fins becomes highest when the transverse pitch decreases and this impact leads to bigger values of the pressure drop and coefficient of heat transfer. On the other hand, the authors stated that an extension of the longitudinal pitch of the tube in the staggered configuration leads to decreases of the Nussit and Euler numbers. Similar results were reported by Rabas et al. [14] for the impact of longitudinal pitch on the heat transfer performance, and the influence on the pressure drop has been confirmed. Fujii et al. [15] developed a numerical 2D laminar flow and heat transfer over tube banks. The study was carried out for an in-line square configuration of the tube banks with five rows with the pitch diameter ratio fixed at 1.5 $\times 1.5$. The boundary conditions for the uniform surface temperature of the tubes. For the three Reynolds numbers 60, 120, and 300, with used the fluid is air $\operatorname{Pr}=0.71$. Antonopoulos [15] presented a 2D analysis of inclined laminar-flow heat transfer in tube assemblies. He used the finite difference technique and curvilinear orthogonal coordinates for purely transverse and flow fully development. Several cases were examined with an inclined flow in the range of $0 \leq \theta \leq 90 \mathrm{o}$ and pitch-to-diameter ratios between 1.25 and 2.0. The Reynolds number varied from 5 to 200 for Pr numbers ranging from 1 to 528. The finite element method was used by Chen et al. [16] and Chen and Weng [17] to solve the Navier-Stokes and energy equations of heat transfer and fluid flow over in-line and staggered configurations of tube banks at the fixed $\mathrm{Pr}$ number of 0.7. Wong and Cleaver [18]presented results for various Reynolds numbers ranging between 20 and 40 and a pitch-to-diameter ratio of 2.0. Chen and Lai [19] studied the effect of pitch-to-diameter ratio and Re number on the number, pressure drag, total drag, and friction drag. The ranges of the pitch-to-diameter ratio and $\mathrm{Re}$ number were 1.7-2.0 and 4-40, respectively. Zdravistch et al. [20] used a finite volume technique and presented results for two pitch-to-diameter ratios of 1.5 and 2.0 with various Reynolds numbers based on the velocity of approach from 54 to 120 at a fixed Pr number of 0.7. It is boosted using the finite volume technique in a $2 \mathrm{D}$ by Cho and Son [21], and 3D by Tsai and Sheu [22]. Beale and Spalding [23] numerically evaluated the heat transfer and fluid flow in a tube bundle.

The main problem in these applications (thermal system) is how to dispersion heat and reduction of power pumping. Estimation of the heat transfer rate and pressure drop are a significant issue for any new configuration in the heat exchanger design. The optimal space of the tubes spacing and fins spacing for the un-finned and finned flat tube heat exchanger in-line in a fixed volume is not specified yet. Therefore, a present 
study attempts to address the optimal design of un-finned and finned flat tubes heat exchanger for laminar forced convection in in-line configurations.

\section{METHODS AND MATERIALS}

Four isothermal heated horizontal flat tube in row. The flat tube have two transverse diameter $d$ and the longitudinal tube diameter $D$, the surface temperature of tube $T_{s}$, placed in the velocity $U_{\infty}$ and the uniform free stream of temperature $T_{\infty}$ in the in-line arrangements. The longitudinal pitch-to-small diameter ratio $S_{1}^{*}=S_{1} / d$ and the transverse pitch-to-small diameter ratio $S_{2}^{*}=S_{2} / d$. The flat tube to be long enough so that it can be neglected the end effect of tube. Therefore, it can be assumed the flow field to be two-dimensional. The configurations flow and calculated fields in flow over in-line flat tube bank as shown in Figure 1. In developing the model, the following assumptions were made: (i) the physical properties of air flow are constant; [15] the air flow is incompressible and laminar flow; and (iii) the steady states flow and heat transfer. The governing equations for two-dimensional continuity, Naviere-Stokes for momentum and energy equation can be written as follows [24]:

The continuity equation:

$$
\frac{\partial U}{\partial X}+\frac{\partial V}{\partial Y}=0
$$

Momentum (Navier-Stokes):

$\mathrm{X}$-direction (u momentum)

$$
\left.\begin{array}{l}
U \frac{\partial V}{\partial X}+V \frac{\partial V}{\partial Y}=-\frac{\partial P}{\partial X}+\frac{1}{R e_{D_{h}}}\left[\frac{\partial^{2} U}{\partial X^{2}}+\frac{\partial^{2} U}{\partial Y^{2}}\right] \\
U \frac{\partial V}{\partial X}+V \frac{\partial V}{\partial Y}=-\frac{\partial P}{\partial X}+\frac{1}{R e_{D_{h}}}\left[\frac{\partial^{2} V}{\partial X^{2}}+\frac{\partial^{2} V}{\partial Y^{2}}\right]
\end{array}\right\}
$$

Y-direction (v momentum)

Energy:

$$
U \frac{\partial \theta}{\partial X}+V \frac{\partial \theta}{\partial Y}=\frac{1}{\operatorname{Pr} \times \operatorname{Re}_{D_{h}}}\left[\frac{\partial^{2} \theta}{\partial X^{2}}+\frac{\partial^{2} \theta}{\partial Y^{2}}\right]
$$

The governing equations were transformed into dimensionless forms upon incorporating the following non-dimensional variables.

$$
\begin{aligned}
& (X, Y)=\frac{(x, y)}{D_{h}}, \quad P=\frac{p}{\rho \times U_{\infty}^{2}}, \quad(U, V)=\frac{(u, v)}{U_{\infty}}, \\
& \theta=\frac{T-T_{\infty}}{T_{s}-T_{\infty}}, \quad R e_{D_{h}}=\frac{U_{\infty} \times D_{h}}{v}, \quad \operatorname{Pr}=\frac{\mu \times C_{P}}{k}
\end{aligned}
$$

where $(x, y)$ are the Cartesian coordinates, $\mathrm{m} ; \rho$ the fluid density, $\mathrm{kg} \mathrm{m}^{-3} ; p$ pressure, $\mathrm{N}$ $\mathrm{m}^{-2} ; U_{\infty}$ the free stream velocity, $\mathrm{m} \mathrm{s}^{-1} ;(u, v)$ the fluid velocity, $\mathrm{m} \mathrm{s}^{-1} ; T$ fluid temperature, ${ }^{\circ} \mathrm{C} ; T_{\infty}$ free stream temperature, ${ }^{\circ} \mathrm{C} ; T_{s}$ surface temperature of tube, ${ }^{\circ} \mathrm{C} ; D_{h}$ hydraulic diameter of tube, $\mathrm{m} ; v$ fluid kinematic viscosity, $\mathrm{m}^{2} \mathrm{~s}^{-1} ; C p$ the fluid specific heat $\mathrm{J} \mathrm{kg}^{-1} \mathrm{~K}^{-1}$ and $k$ the fluid thermal conductivity $\mathrm{W} \mathrm{m}^{-1} \mathrm{~K}^{-1}$.

The physical system considered in the present study is displayed in Figure 1. The boundary conditions used for the solution domain are uniform inlet velocity, fully developed outflow, and a combination of symmetry and no-slip tube surfaces on the bottom and top boundaries. The boundary conditions prescribed for $U, V$ and $\theta$ are summarized in Table 1. 


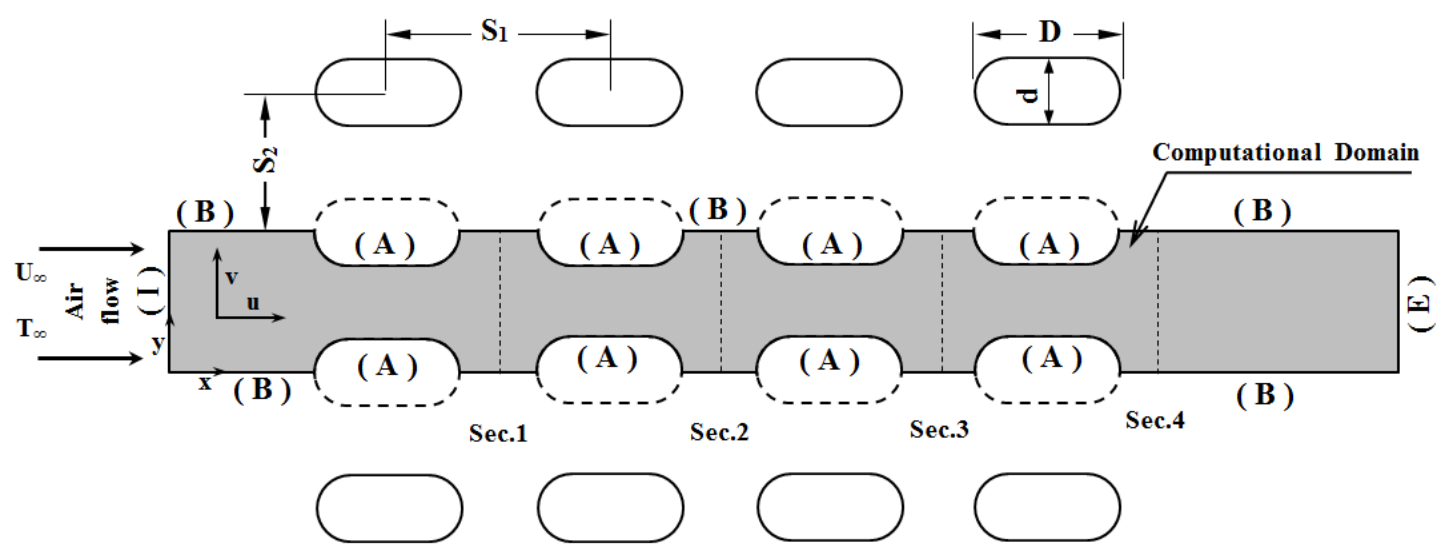

Figure 1. In-line flat tube bank: (a) tube arrangement; (b) computational domain.

The set of conservation Eq. (3) and Eq. (4) can be written in general form in Cartesian coordinates as Eq. (5):

$$
\frac{\partial(U \phi)}{\partial X}+\frac{\partial(V \phi)}{\partial Y}=\frac{\partial}{\partial X}\left(\Gamma \frac{\partial \phi}{\partial X}\right)+\frac{\partial}{\partial Y}\left(\Gamma \frac{\partial \phi}{\partial Y}\right)+S_{\phi}
$$

The continuity equation, Eq. (2) has no diffusion and source terms. It will be used to derive an equation for the pressure correction. The grid generation scheme based on elliptic partial differential equations is used in the present study to generate the curvilinear coordinates. Eq. (5) can be transformed from the physical domain to the computational domain according to the following transformation $\zeta=\zeta(x, y), \eta=\eta(x, y)$. The final form of the transformed equation can be written as Eq. (6):

$$
\frac{\partial}{\partial \zeta}\left(\phi G_{1}\right)+\frac{\partial}{\partial \eta}\left(\phi G_{2}\right)=\frac{\partial}{\partial \zeta}\left(\frac{\Gamma}{J}\left(\alpha \frac{\partial \phi}{\partial \zeta}-\gamma \frac{\partial \phi}{\partial \eta}\right)\right)+\frac{\partial}{\partial \eta}\left(\frac{\Gamma}{J}\left(\beta \frac{\partial \phi}{\partial \eta}-\gamma \frac{\partial \phi}{\partial \zeta}\right)\right)+J S_{\phi}
$$

Table 1 . The boundary conditions for $U, V$ and $\theta$.

\begin{tabular}{llccc}
\hline & & $U$ & $V$ & $\theta$ \\
\hline ( I ) & Inlet & 1 & 0 & 0 \\
( E ) & Exit & $\partial U / \partial X$ & $\partial V / \partial X=0$ & $\partial \theta / \partial X=0$ \\
( A ) & Tube surface & 0 & 0 & 1 \\
( B ) & Symmetry & $\partial U / \partial Y=0$ & 0 & $\partial \theta / \partial Y=0$ \\
\hline
\end{tabular}

The overall heat transfer coefficient can be estimated in the dimensionless form by the average Nusselt number $\mathrm{Nu}$ is defined as:

$$
N u=\frac{\bar{h} \times D_{h}}{k}
$$


The differential pressure measurements was the finality of measuring the pressure drop across each of change the free stream velocity in all experiments as shown in Figure 2. The experimental work includes the attainment of temperature data using TESTO highly accurate thermometer, model TESTO 110 the nominal range of $-50{ }^{\circ} \mathrm{C}$ to $+150{ }^{\circ} \mathrm{C}$ the temperature thermometer resolution is $0.1^{\circ} \mathrm{C}$ and the accuracy around \pm 0.2 ${ }^{\circ} \mathrm{C}$. The thermistors were calibrated in the laboratory for the purpose of finding the deviation limits. The details of the calibration are given in Ishak et al. [25] and Tahseen et al. [26]. Started each run by selecting the voltage and current supply to the cartridge heaters. The selected air velocity of free stream, then we waited for 1.5-2.0 hour while monitor the changes in voltage, current, $T_{\text {bef }}, T_{i n, 1}-T_{i n, 2}, T_{s, 1}-T_{s, 3}$ and $T_{\text {out }, 1}-T_{\text {out }, 2}$. The relative deviation in the voltage, current and temperature were range $0.3 \%-2.6 \%, 1.7 \%-$ $3.6 \%$ and $0.16 \%-0.7 \%$, respectively. These changes were estimated relatively by repeating the same value $R e_{D h}$ value within $7.5-8.0$ hours. It is noted that these relative changes are small when compared with the uncertainties in the relevant measurements.

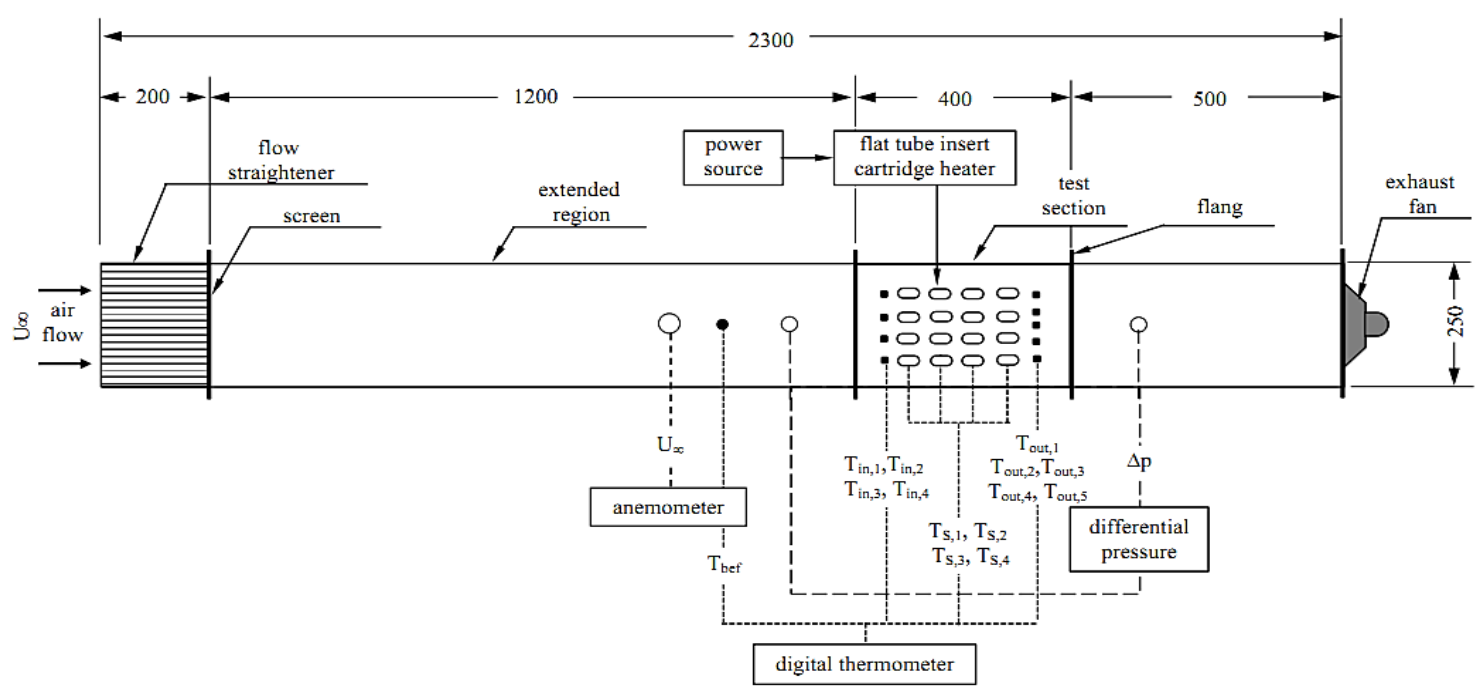

Figure 2. Schematic displayed of the experimental approach, all dimensions (mm).

\section{RESULTS AND DISCUSSION}

This study is compared with numerical predictions at the similar conditions of tube available in the literature. Table 2 presents the comparison of the average Nusselt number $(\overline{\mathrm{Nu}})$ for two-dimensional of in-line arrangements between the present study and Bahaidarah et al. [27]. The geometrical parameters of the tube configuration are presented in Table 2. Reynolds number of 100 and 400 are considered for prediction of average Nusselt number. The solution domain was divided into many Heat Exchanger Modules (HEMs). One flat tube putted in centre of each HEM and bound by the inlet and outlet surface in the left and right side, respectively. These bound at the mid-section among two tubes in flow direction. The results are closely agreed within error of $3.6 \%$. These deviations are appeared due to ignore approximated of the dimensionless temperature at the inlet and outlet of the each HEM. A comparison with the experimental results was carried out to validate the numerical results obtained through the finite volume codes for the cylinder shape for in-line arrangement. The completion of the code validation based on the of overall heat transfer rate. 
Figure 3 presents the comparisons between present simulations with the experimental results of Stanescu et al. [28]. The deviation increases with increasing of Reynolds number as shown in Figure 3. The maximum deviation between the present study and the Stanescu et al. [28] about 3.6\% and 3.9 for the Reynolds number $(=100)$ and $(=200)$, respectively. These deviations are shows because of the ignoring the influence of the change thermal properties with temperature and the approximate in the thermal properties fluid flow and heat flux supplier on cylinder. This general trend is coincidence with previous works reported by Matos et al. [29]. The calibration parameters are employed to the present developed models with experimental study. The predicted results are good agreement with the experimental results. The average deviations in overall heat transfer and power pumping for in-line configuration are within $4.1 \%$ and $7.3 \%$, respectively.

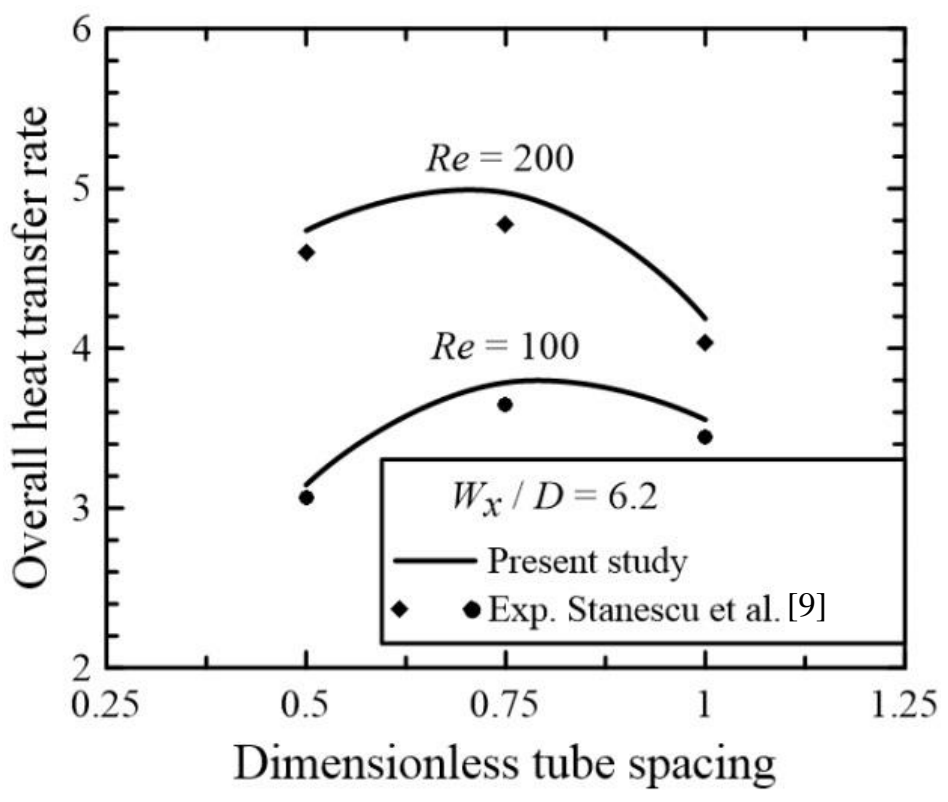

Figure 3. Comparison between the current numerical results with previous published experimental results for the overall heat transfer rate.

Variation of dimensionless overall heat transfer rate in terms dimensionless tubes spacing and dimensionless fins density for several Reynolds number is demonstrated in Figure 4. It can be seen that the maximum value of dimensionless overall heat transfer rate found in the optimal dimensionless tubes spacing and optimal dimensionless fins density for all Reynolds number. The dimensionless overall heat transfer rate is always increases with an increase of the Reynolds number. It can be explained by the increasing of dimensionless overall heat transfer rate to upper value and return down to low value. This behaviour are appears due to increases of the air flow rate until the optimal tubes spacing or optimal fins spacing [29]. It is expected that the increase in the distance between tubes rows or fins spacing more than the optimal geometry could lead to reduce or blockage in the air flow at the channel between two tube rows or two fins [30]. 
Table 2. The comparison between the present simulation and Bahaidarah et al. [27], geometrical parameters and average Nusselt number.

\begin{tabular}{|c|c|c|c|c|c|c|c|}
\hline & $\begin{array}{c}\text { Bahaidarah } \\
\text { et al. [8] }\end{array}$ & $\begin{array}{c}\text { Present } \\
\text { study }\end{array}$ & $\begin{array}{l}\text { diff. } \\
(\%)\end{array}$ & & $\begin{array}{c}\text { Bahaidarah } \\
\text { et al. [8] }\end{array}$ & $\begin{array}{c}\text { Present } \\
\text { Study }\end{array}$ & $\begin{array}{l}\text { diff. } \\
(\%)\end{array}$ \\
\hline \multicolumn{5}{|c|}{ Re- 100} & \multicolumn{3}{|c|}{$\mathrm{Re}=400$} \\
\hline $\begin{array}{l}\text { 2nd } \\
\text { HEM }\end{array}$ & 14.61 & 15.02 & 2.730 & $\begin{array}{l}\text { 2nd } \\
\text { HEM }\end{array}$ & 18.07 & 18.64 & 3.058 \\
\hline $\begin{array}{l}\text { 3rd } \\
\text { HEM }\end{array}$ & 14.60 & 14.92 & 2.145 & $\begin{array}{l}3 \text { rd } \\
\text { HEM }\end{array}$ & 17.33 & 17.97 & 3.562 \\
\hline $\begin{array}{l}\text { 4th } \\
\text { HEM }\end{array}$ & 14.60 & 14.86 & 1.750 & $\begin{array}{l}\text { 4th } \\
\text { HEM }\end{array}$ & 17.29 & 17.56 & 1.538 \\
\hline
\end{tabular}

Geometric parameters: $\mathrm{L} / \mathrm{Da}=4 ; \mathrm{H} / \mathrm{Da}=2$

$D a$ : transverse flat tube diameter, $L$ : domain length, $H$ : channel height, $D_{H}$ : hydraulic diameter; $\overline{N u}=\bar{h} \times D_{H} / k_{\mathrm{a}} ; \%$ of deviation $=\left|\overline{N u}_{\text {pres }}-\overline{N u}_{\text {prov }}\right| / \overline{N u}_{\text {pres }} \times 100$
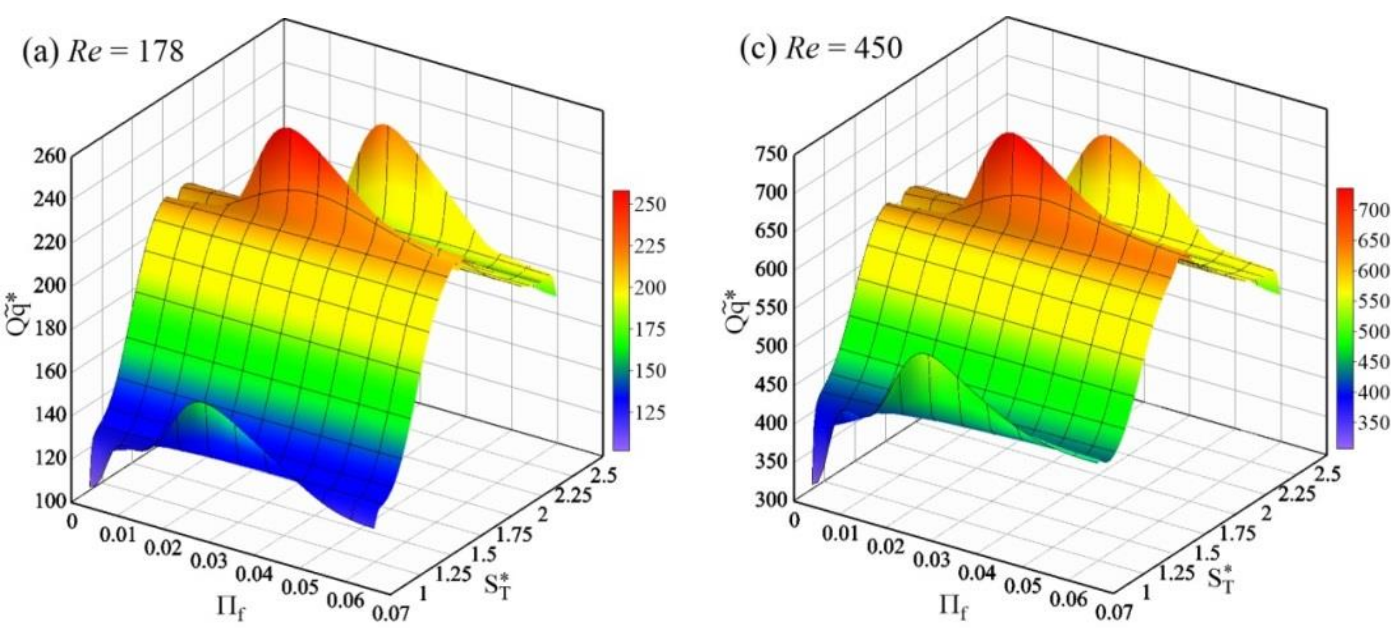

Figure 4. Variation of overall dimensionless heat transfer rate against dimensionless tubes spacing and dimensionless fins density.

The predicted and experimental results dimensionless overall heat transfer rate density as a function of Reynolds number for dimensionless tubes spacing and dimensionless fins density were plotted in Figure 5. Owing to the resultant increase in the Reynolds number, this eventually leads to an increase in the overall dimensionless heat transfer rate for dimensionless tubes spacing and dimensionless fins density. It was observed that the higher dimensionless overall heat transfer rate in the optimal dimensionless fins density is 0.025 , for all Reynolds number and tubes spacing tested. To the contrary, the deviation at the higher Reynolds number is strongly interacted with the dimensionless tubes spacing. The dimensionless fins spacing effect on the dimensionless overall heat transfer rate increase is noticeable at high Reynolds numbers because the thin of thermal boundary layer gets compared to the low Reynolds number [31]. However, there is a discrepancy between the numerical and experimental results, where the mean deviations within $\pm 4.1 \%$. As can be seen from Figure $5(\mathrm{~b})$ at the optimal tube-to-tube space, is 1.6, the increasing in the dimensionless overall heat 
transfer rate for all Reynolds number and dimensionless fins density tested are small with the lower and higher value about $\pm 17.9 \%$ and $\pm 2.23 \%$ for higher and lower Reynolds number, respectively.

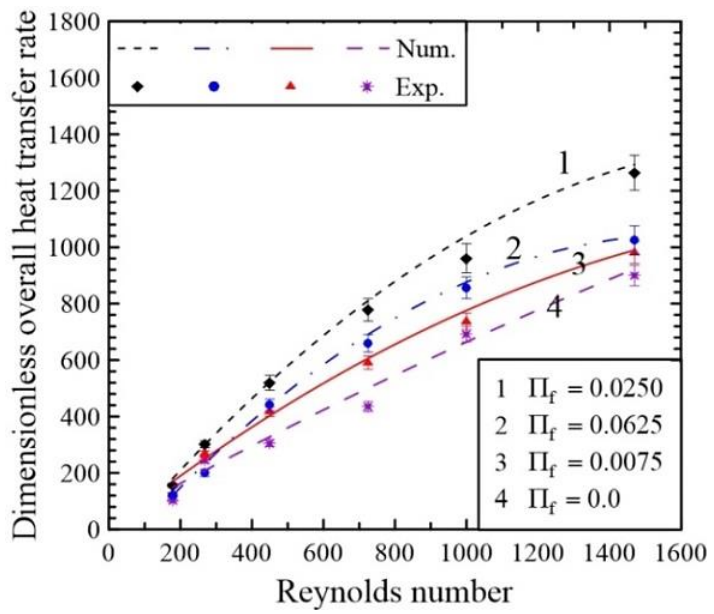

(a) $S_{\mathrm{T}}^{*} \cong 0.9$

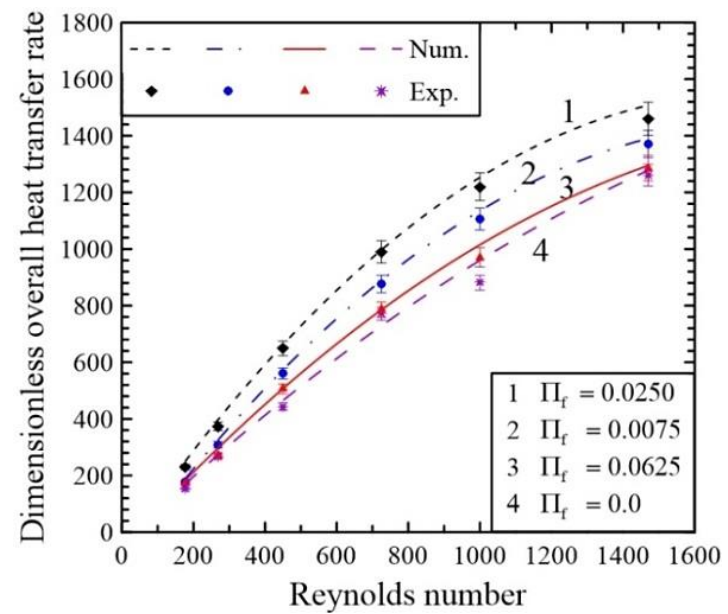

(b) $S_{\mathrm{T}}^{*} \cong 2.4$

Figure 5. Dimensionless overall heat transfer rate a function of Reynolds number for dimensionless tubes spacing and dimensionless fins density for in-line configuration.

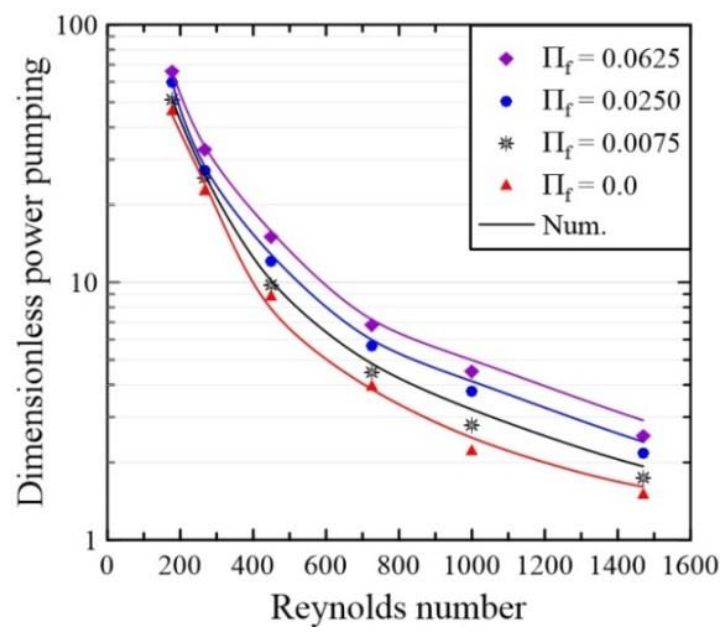

(a) $S_{\mathrm{T}}^{*} \cong 0.9$

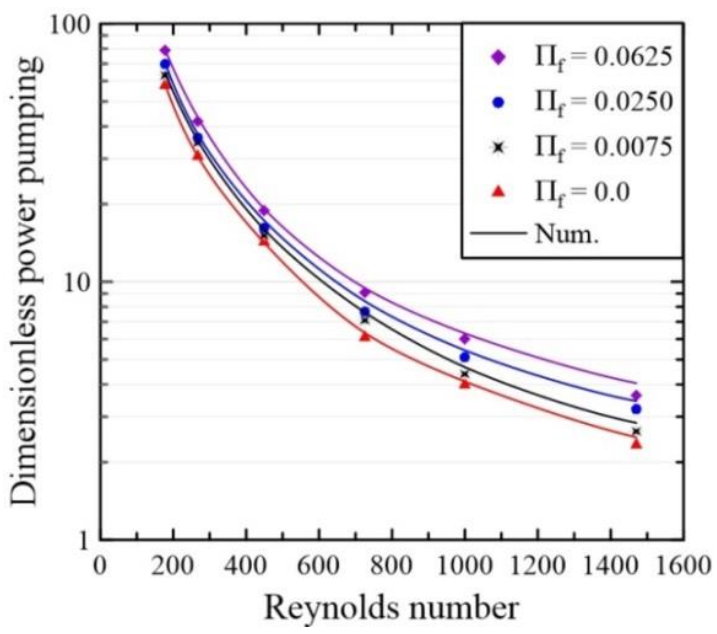

(b) $S_{\mathrm{T}}^{*} \cong 2.4$

Figure 6. Influence of Reynolds number on dimensionless pumping power minimization with respect to the dimensionless fins density and tube-to-tube spacing.

Figure 6 shows the effects of Reynolds number on the predicted and experimental dimensionless pumping power results with the dimensionless tubes spacing and dimensionless fin density. The dimensionless pumping power increases with increasing response Reynolds numbers for all geometrical parameters such as dimensionless tubes spacing and dimensionless fins density. It can be observed that at a lower Reynolds numbers the fewer influence of the dimensionless fin density on the dimensionless pumping power while, it is more significant at higher Reynolds numbers. On the other hand, the dimensionless pumping power decreased with increase of dimensionless fin density. This is because of the reduction in the channel flow width 
between two fins and increase in the air velocity. This is due to merge of the boundary layers between two fins and suppressed the horseshoe vortices around the tube and decreases the pressure drop. Thus, the impact of reduction of fin spacing depends primarily on the air velocity, which controls the boundary layers [9].

\section{CONCLUSIONS}

A comparison with the experimental results was carried out to validate the numerical results obtained through the finite volume codes for the cylinder shape for in-line arrangement. The predicted results are good agreement with the experimental results. The average deviations in overall heat transfer and power pumping for in-line configuration are within $4.1 \%$ and $7.3 \%$, respectively. The dimensionless overall heat transfer rate is always increases with an increase of the Reynolds number. The deviation at the higher Reynolds number is strongly interacted with the dimensionless tubes spacing. The dimensionless fins spacing effect on the dimensionless overall heat transfer rate increase is noticeable at high Reynolds numbers. The increasing in the dimensionless overall heat transfer rate for all Reynolds number and dimensionless fins density tested are small with the lower and higher value about $\pm 17.9 \%$ and $\pm 2.23 \%$ for higher and lower Reynolds number, respectively. The dimensionless pumping power increases with increasing response Reynolds numbers for dimensionless tubes spacing and dimensionless fins density. The dimensionless pumping power decreased with increase of dimensionless fin density.

\section{ACKNOWLEDGEMENTS}

The authors would like to acknowledgements the Universiti Malaysia Pahang for sponsoring the presented work under the FRGS project no. RDU120103.

\section{REFERENCES}

[1] Bergman TL, Incropera FP, Lavine AS. Fundamentals of heat and mass transfer: John Wiley \& Sons; 2011.

[2] Tahseen TA, Ishak M, Rahman MM. Laminar forced convection heat transfer over staggered circular tube banks: A CFD approach. Journal of Mechanical Engineering and Sciences. 2013;4:418-30.

[3] Nawi MRM, Mamat AMI, Ismail H. Numerical heat transfer analysis of waste heat exchanger for exhaust gas energy recovery. Journal of Mechanical Engineering and Sciences. 2015;8:1498-506.

[4] Hussein AM, Sharma KV, Bakar RA, Kadirgama K. Heat transfer enhancement with nanofluids - A review. Journal of Mechanical Engineering and Sciences. 2013;4:452-61.

[5] Bejan A, Kraus AD. Heat transfer handbook: John Wiley \& Sons; 2003.

[6] Bahaidarah H. A numerical study of heat and momentum transfer over a bank of flat tubes: Texas A\&M University; 2005.

[7] Tahseen TA, Ishak M, Rahman MM. A numerical study of forced convection heat transfer over a series of flat tubes between parallel plates. Journal of Mechanical Engineering and Sciences. 2012;3:271-80.

[8] Min J, Webb RL. Numerical analyses of effects of tube shape on performance of a finned tube heat exchanger. Journal of Enhanced Heat Transfer. 2004;11. 
[9] Tahseen TA, Rahman MM, Ishak M. An experimental study of air flow and heat transfer over in-line flat tube bank. International Journal of Automotive and Mechanical Engineering. 2014;9:1487-500.

[10] Ishak M, Tahseen TA, Rahman MM. Experimental investigation on heat transfer and pressure drop characteristics of air flow over a staggered flat tube bank in crossflow. International Journal of Automotive and Mechanical Engineering. 2013;7:900-11.

[11] Al- Doori WHAR. Enhancement of natural convection heat transfer from the rectangular fins by circular perforations. International Journal of Automotive and Mechanical Engineering. 2011;4:428-36.

[12] Nir A. Heat transfer and friction factor correlations for crossflow over staggered finned tube banks. Heat Transfer Engineering. 1991;12:43-58.

[13] Sparrow E, Samie F. Heat transfer and pressure drop results for one-and tworow arrays of finned tubes. International journal of heat and mass transfer. 1985;28:2247-59.

[14] Rabas T, Taborek J. Survey of turbulent forced-convection heat transfer and pressure drop characteristics of low-finned tube banks in cross flow. Heat transfer engineering. 1987;8:49-62.

[15] Fujii M, Fujii T, Nagata T. A numerical analysis of laminar flow and heat transfer of air in an in-line tube bank. Numerical Heat Transfer. 1984;7:89-102.

[16] Chen Y, Fiebig M, Mitra N. Conjugate heat transfer of a finned oval tube part A: flow patterns. Numerical Heat Transfer, Part A Applications. 1998;33:371-85.

[17] Chen CH, Weng F-B. Heat transfer for incompressible and compressible fluid flows over a heated cylinder. Numerical heat transfer. 1990;18:325-42.

[18] Wong KL, Cleaver J. Finite element solutions of laminar flow and heat transfer of air in a staggered and an in-line tube bank. International journal of heat and fluid flow. 1986;7:291-300.

[19] Chen H-T, Lai J-R. Study of heat-transfer characteristics on the fin of two-row plate finned-tube heat exchangers. International Journal of Heat and Mass Transfer. 2012;55:4088-95.

[20] Zdravistch F, Fletcher CA, Behnia M. Numerical laminar and turbulent fluid flow and heat transfer predictions in tube banks. International Journal of Numerical Methods for Heat \& Fluid Flow. 1995;5:717-33.

[21] Cho J, Son C. A numerical study of the fluid flow and heat transfer around a single row of tubes in a channel using immerse boundary method. Journal of mechanical science and technology. 2008;22:1808-20.

[22] Tsai S, Sheu TW. Some physical insights into a two-row finned-tube heat transfer. Computers \& fluids. 1998;27:29-46.

[23] Beale S, Spalding D. Numerical study of fluid flow and heat transfer in tube banks with stream-wise periodic boundary conditions. Transactions of the CSME. 1998;22:397-416.

[24] Tahseen TA, Ishak M, Rahman M. Performance predictions of laminar heat transfer and pressure drop in an in-line flat tube bundle using an adaptive neurofuzzy inference system (ANFIS) model. International Communications in Heat and Mass Transfer. 2014;50:85-97.

[25] Ishak M, Tahseen TA, Rahman MM. Experimental investigation on heat transfer and pressure drop characteristics of air flow over a staggered flat tube bank in cross-flow. International Journal of Automotive and Mechanical Engineering. 2013;7:900-11. 
[26] Tahseen TA, Ishak M, Rahman MM. An experimental study air flow and heat transfer over in-line flat tube bank. International Journal of Automotive and Mechanical Engineering. 2014;9:1487-500.

[27] Bahaidarah HM, Anand N, Chen H. A numerical study of fluid flow and heat transfer over a bank of flat tubes. Numerical Heat Transfer, Part A: Applications. 2005;48:359-85.

[28] Stanescu G, Fowler A, Bejan A. The optimal spacing of cylinders in free-stream cross-flow forced convection. International Journal of Heat and Mass Transfer. 1996;39:311-7.

[29] Matos R, Vargas J, Laursen T, Saboya F. Optimization study and heat transfer comparison of staggered circular and elliptic tubes in forced convection. International Journal of Heat and Mass Transfer. 2001;44:3953-61.

[30] Xie G, Wang Q, Sunden B. Parametric study and multiple correlations on airside heat transfer and friction characteristics of fin-and-tube heat exchangers with large number of large-diameter tube rows. Applied Thermal Engineering. 2009;29:1-16.

[31] Bhuiyan AA, Amin MR, Islam AS. Three-dimensional performance analysis of plain fin tube heat exchangers in transitional regime. Applied Thermal Engineering. 2013;50:445-54. 